\title{
Alzheimer's Disease Pathogenesis: The Role of Aging
}

\section{Denham Harman, M.D., Ph.D. ${ }^{1}$}

Abstract

Alzheimer's disease (AD) is characterized by intraneuronal fibrillary tangles, plaques and cell loss. Brain lesions in both sporadic AD (SAD) and familial AD (FAD) are the same, and in the same distribution pattern, as those in individuals with Down's syndrome (DS) and in smaller numbers in non-demented older individuals. Dementia onset is around 40 years for Down's syndrome, 40-60 years for FAD, and usually over 60 years for SAD. The different categories of $A D$ may be due to processes which augment to different degrees the innate cellular aging rate, i.e. mitochondrial superoxide radical (SO) formation. Thus, they increase the rate of accumulation of $A D$ lesions. This lowers the age of onset into the dementia ranges associated with Down's syndrome, FAD, and SAD, and concomitantly, shortens life spans. Faster aging lowers $A D$ onset age by decreasing the onset age for neurofibrillary tangle formation and neuronal loss, and the age when brain intercellular $\mathrm{H}_{2} \mathrm{O}_{2}$ can activate microglial cells. The early AD onset in Down's syndrome is attributed to a defective mitochondrial complex 1 . The proteins associated with FAD and their normal counterparts undergo proteolytic processing in the endoplasmic reticulum (ER). The mutated compounds increase the ratio of $B A_{42}$ to $B A_{40}$ and likely also down-regulate the ER calcium $\left(\mathrm{Ca}^{++}\right)$ buffering activity. Decreases in $\mathrm{ER} \mathrm{Ca}^{++}$content should increase the mitochondrial $\mathrm{Ca}^{++}$ pool, thus enhancing SO formation. SAD may be due to increased SO formation caused by mutations in the approximately 1000 genes involved in mitochondrial biogenesis and function. The hypothesis suggests measures to prevent and treat.

1. University of Nebraska M edical Center, , Nebraska 681984635

\section{Introduction}

Alzheimer's disease (AD) is the chief cause of dementia. It is a systemic disorder whose major manifestations are in the brain. ${ }^{2-4}$ The majority of cases ${ }^{5}$ (90-95 percent) are sporadic (SAD). The remaining 510 percent are familial (FAD). ${ }^{5}$ Most FAD cases are caused by mutations in the gene for presenilin 1 (PS1) on chromosome 14, 5,6 some by mutations in the genefor presenilin 2 (PS2) on chromosome 1,7 while a few have mutations in the gene for the amyloid precursor protein (APP) on chromosome 21.7.8

$A D$ is characterized by intraneuronal fibrillary tangles, plaques, and cell loss; $1,2, \cdot 12$ major steps in pathogenesis have been summarized. ${ }^{4}$ Plaques contain $\beta A$ peptides (mainly $\beta A_{42}$ ), formed by proteolysis of APP, that have aggregated into fibrils. Most peptides are in plaques that are not recognized by the usual Congo red and thioflavin methods, i.e., preamyloid plaques-also termed diffuse or amorphous plaques. The minor peptide fraction, formed by the action of free radicals on the fibrillary form of the $\beta A$ peptide present in preamyloid, ${ }_{1}^{13}$ is in plaques recognized by Congo red, i.e. amyloid plaques. Amyloid formation is generally associated with the clinical manifestations of AD.

The brain lesions in both SAD and FAD are the same, and in the same distribution pattern, as those seen in individuals with Down's syndrome(DS), ${ }^{1,14}$ and in smaller numbers in non-demented older individuals. ${ }^{15,16}$

Dementia onset is around age 40 for Down's syndrome, ${ }^{14}$ 40-60 years for FAD, ${ }^{5}$ and usually 60 years for SAD. ${ }^{5}$ Lower dementia onset ages are associated with shorter life spans. Extensive studies of AD have yet to result in a generally accepted hypothesis on pathogenesis. $17-20 \mathrm{M}$ ajor emphasis has been placed on the role of amy- 
loid, ${ }^{19-24}$ the neurotoxin formed by the action of free radicals on preamyloid. ${ }^{12,13}$

\section{Hypothesis on Pathogenesis of Alzheimer's Disease}

The frequent presence of $A D$ lesions in normal older persons, coupled with the association between lower dementia onset ages and shorter life spans, prompted the hypothesis that the different categories of $A D$ are the result of processes which augment to different degrees the innate cellular aging rate, i.e., mitochondrial superoxide radical (SO) formation. Thus, they increase the rate of accumulation of $A D$ lesions. This lowers the age of onset of the dementia of old age into the dementia ranges associated with Down's syndrome, FAD, and SAD, and concomitantly, shorten life spans.

\section{Aging}

Aging is the accumulation of diverse deleterious changes in the cells and tissues that increase the risk of disease and death. ${ }^{25,26}$ $M$ any theories have been advanced to account for aging. No theory is generally accepted. The Free Radical Theory of A ging ${ }^{27,28}$ (FRTA) is a promising hypothesis; the subsequent discussion is based on the assumption that it is correct. The FRTA postulates that aging changes are caused by free radical reactions. Those responsible for the innate cellular aging process largely stem from the superoxide radicals (SO) formed by the mitochondria at an increasing rate with age in the course of normal metabolism. These, plus the free radicals arising from suboptimal living conditions, ${ }^{29}$ cause "aging".

Involvement of the Aging process in Formation of the Characteristic Lesions of $A D$

Intraneuronal Fibrillary Tangles: The latter permits phosphorylated tau to selfassemble and form paired helical filaments and, in turn neurofibrillary tangles, while concomitantly the destabilized microtubules breakdown. Cells with neurofibrillary tangles eventually die.
Neuritic plaques. The progresiveincrease in cellular superoxide radical formation with age ${ }^{30,31} \mathrm{AD}$ should be reflected in rising intercellular levels of $\mathrm{H}_{2} \mathrm{O}_{2}$ in the brain. At some age and in some locations, these levels could begin to exceed the threshold for the activation of microglia cells in a manner akin to the up-regulation of the synthesis of cytokines IL- 8 and TNF- $\alpha$ by dendritic cells.32 Then, free radicals formed by activated microglia could serve to catalyze the oxidative conversion of preamyloid in the microglia area to amyloid, and simultaneously initiate the inflammation $1^{9,33}$ involved in neuritic plaque formation and neuronal cell loss.

Thus, increasing mitochondria superoxide radical production lowers AD onset age by decreasing the onset age of AD lesions. How apolipoprotein E4 lowers AD onset age is not known. The 02 mediated interaction between ApoE4 ${ }^{34}$ and $\beta A 4$ suggests a possible explanation: Reaction of tissue 02 with ApoE4 may serve as a catalyst for the slow oxidative compaction of preamyloid, a process which results eventually in formation of amyloid. Thus, when $\mathrm{H}_{2} \mathrm{O}_{2}$-induced microglia activation occurs, less time is required to complete the compaction. Hence, the age of onset of clinical symptoms of AD is decreased, more so the longer the period of ApoE4-associated compaction.

Augmentation of the Innate Aging Rate Sporadic AD: Increases in mitochondrial SO formation in SAD is attributed 4 to accumulating free radical-induced mutation(s) in one or more of the approximately 1000 mtDNA and nucDNA genes involved in mitochondrial biogenesis and function. ${ }^{35}$ This should decrease the age when the normally accumulating $A D$ lesions increase into the $A D$ dementia onset ages associated with SAD, and concomitantly, shortens life span.

In view of the above it is not surprising that efforts to find the gene(s) responsiblefor sporadic AD havebeen inconclusive. ${ }^{1936-38}$ This disorder could be initiated by one or more of 
a large number of combinations of mutations of the genes associated with mitochondrial function, e.g., those influencing cytochrome oxidase. ${ }^{39}$ Identification of the initiating mutation(s) would be expected to be made progressively more difficult with time by the continuing accumulation of mutations throughout life.

Familial AD: APP, PS1, and PS2, as well as their mutated forms, undergo proteolytic processing in the endoplasmic reticulum (ER) membrane..$^{19}$ These compounds are ubiquitously expressed transmembrane proteins; APP has a single transmembrane domain while PS1 and PS2 have six to nine. ${ }^{40}$ The turnover time of normal APP is short (20-30 minutes). ${ }^{40,41}$ Turnover times of PS1 and PS2 arealso short, about 15 minutes; 42 that of the complex formed from the $\mathrm{N}$ - and C-terminal fragments is apparently greater than 12 hours. ${ }^{43}$ Mutations in the APP and the presenilins should further shorten turnover times. ${ }^{44}$

Cleavage of APP by $\alpha$ - or $\beta$-secretase produces, respectively, membrane-bound 83and 99-residue C-terminal fragments. These fragments are cleaved by $\gamma$-secretase, apparently formed ${ }^{45}$ from the $\mathrm{N}$ - and C-terminal fragments of either PS1 or PS2; the products of the C99 cleavage include the $\beta_{40}$ and $ß A_{42}$ peptides. Mutants of the presenilins increase the fraction of $\beta_{42,}{ }^{19}$ and increase it further with mutated APP.19

The calcium buffering activity of the ER is modulated by theATPasecalcium pumps, ${ }^{46-}$ ${ }^{48}$ located in the ER membrane ${ }^{49,50}$ and by the associated $\mathrm{Ca}^{2++}$ release channels.15.52 $\mathrm{M}$ any compounds influence ER calcium content, including: 1) phospho-lamban,53-55 2) the ganglioside GM 1 and GM 3;5,57 3) 6-gingero| ${ }^{58}$ and ellagic acid;58 4) procaine, ${ }^{4}$ caffeine, thapsigargin, and dantrolene; ${ }^{49}$ ) the erythrocyte isoenzyme of acylphosphatase ${ }^{59}$-this enzyme inhibits the $\mathrm{Ca}^{2+}$ pump by hydrolysing the phospho-intermediate formed during the catalytic cycle of the calcium ATPase.

It seems very likely that mutations in APP or the presenilins decrease ER calcium buffering, in a manner akin to that of one or more of the substances known to influence it, resulting in compensatory increases in other calcium pools, particularly in mitochondria. The foregoing is strongly supported by studies with cultured neurons. ${ }^{60-62}$ Increases in mitochondrial calcium content enhances superoxide radical formation, ${ }^{63}$ and in turn, lowers the $A D$ onset age.

Clinical manifestations of FAD, and death, occur at significantly lower ages than for those with SAD. This can be attributed to a combination of one or more of the following: 1) Mitochondrial superoxide radical formation is increased secondary to the increased $\mathrm{O}_{2}$ consumption associated with increased turnover of the mutated forms of APP and of the presenilins; 2) Increased formation of the more amyloidogenic forms of $A B$, i.e, $\left.A ß_{42} ; 3\right)$ Down-regulation of thecalcium buffering activity of the ER leading to increased mitochondrial superoxide radical formation; 4) Amyloid-associated inflammatory responses.

\section{Down's Syndrome (DS)}

Individuals with this disorder have three copies of chromosome 21 rather than the normal two. Chromosome 21 codes for both superoxide dismutase (SOD) and APP; these gene products are increased in the cells of individuals with DS. ${ }^{64}$ Persons with this disorder display premature aging; ${ }^{64,65}$ manifestations include rapid aging of the skeletal system and skin, early menopause, short life span, and AD-like pathology ${ }^{14}$ after about age 40. The first indication of the latter is generally apathy ${ }^{64}$ and recent memory loss. ${ }^{66}$

The early onset of $A D$ in individuals with Down's syndrome is attributed to an enhanced rate of neuronal SO formation; 67,68 probably a result of a defect in complex 1 of the respiratory chain. ${ }^{67}$ Thus, the early appearance of $A D$ in individuals with Down's syndrome, as with SAD and FAD, may be largely caused by a higher than normal rate of increase with age of SO. 
Dementia Pugilistica (DP): An AD Related Disorder

A blow(s) to the head is a risk factor for Alzheimer's disease. ${ }^{69}$ Repeated blows are associated with DP - the punch drunk syndrome. ${ }^{70,71}$ The severity of the syndrome correlates with the length of the boxing career and total number of bouts, and has an overall incidence of about $17 \%$ in professional boxers which rises with age..$^{70,71}$

There are numerous neurofibrillary tangles in the cerebral cortex, particularly in the temporal lobe. ${ }^{70,71}$ In contrast to AD, neuritic plaques are few while diffuse preamyloid plaques ${ }^{70}$ are abundant; the diffuse plaques can form within days after head injury. ${ }^{72}$ M ost cases show evidence of past brain hemorrhage. ${ }^{73}$

The initiating steps in pathogenesis of DP may be similar to those of sporadic AD. Extracellular iron, e.g., in the form of heme, may disrupt calcium homeostasis by increasing the influx of calcium through the neuronal membrane by: 1) catalyzing oxidative alterations in the membrane, and 2) increasing intracellular $\mathrm{H}_{2} \mathrm{O}_{2}$ concentrations (by catalyzing the aggregation rate of ex- tracellular BA peptides to form amyloid, this in turn perturbs the neuronal membrane so as to activate an NADPH oxidase $^{74}$ ). Increasing neuronal calcium concentration in the foregoing manner should result in neurofibrillary tangle formation. ${ }^{4}$

The relative paucity of neuritic plaques in boxers is probably because their brain intercellular levels of $\mathrm{H}_{2} \mathrm{O}_{2}$, like those of the average person, are below the level needed to induce activation of microglial cells.

\section{Comment}

The brain lesions of SAD, FAD, those seen after about age 40 in individuals with Down's syndrome, and in older non-demented persons, are the same and have the same distribution, but differ in the age of onset and the degree of involvement. The foregoing prompted the hypothesis that the different categories of $A D$ are the result of processes (Table 1, below) which augment to different degrees theinnate cellular aging rate, i.e., rate of mitochondrial $\mathrm{SO}$ formation. These lower AD dementia onset ages to those associated with Down's syndrome, FAD, and SAD, and concomitantly, shortens life spans.

Table 1. Processes which augment to different degrees the innate cellular aging process, i.e., mitochondrial superoxide radical formation, lower the age when the normally accumulating AD lesions increase into the dementia ranges associated with SAD, FAD, and Down's syndrome.

$A D$ category Processes

SAD: Accumulation of free radical-induced mutation(s) in one or more of the approximately $1000 \mathrm{mtDNA}$ and nucDNA genes involved in mitochondrial biogenesis and function.

FAD: Mutations in APP or the presenilins that down-regulate ER calcium buffering capacity. This increases mitochondrial calcium levels resulting in enhanced $\mathrm{SO}$ formation.

DS: Defective complex 1 of the mitochondrial respiratory chain. 
The age of the appearance of neurofibrillary tangles and of that for neuritic plaques are not necessarily the same. The innate aging process serves as the final common pathway for $A D$.

The hypothesis suggests practical measures to prevent and treat. 4,75,76 Thus the age of onset of all categories of AD may be increased by measures to delay conversion of preamyloid to amyloid, e.g., minimize the expected rise of tissue $\mathrm{H}_{2} \mathrm{O}_{2}$ in the brain with age using compounds such as lipoic acid or dehydroascorbic acid. 75,76

\section{References}

1. Katzman R: Alzheimer's disease. N Eng J Med, 1986; 314: 964-973.

2. Katzman R and Saitoh T: Advances in Alzheimer's disease. FASEB J, 1991; 5: 278-286.

3. Baker AC, Ko L-W and Blass JP: Systemic manifestations of Alzheimer's disease. Age, 1988; 11: 60-65.

4. Harman D: Free radical theory of aging: Alzheimer's disease pathogenesis. Age, 1995; 18: 97-119.

5. Goedert M, Strittmatter J, and Roses AD: Risky apoliporotein in brain. Nature, 1994; 372: 45-46.

6. Schellenberg GD, Birdd TD, Wijsman EM, et al: Gentic linkage evidence for a familial Alzheimer's disease locus on chromosome 14. Science, 1992; 258: 668-671.

7. Levy-Lahad EW, E.M. Wijsman EM, E. NemensE, et al: A familial Alzheimer's disease locus on chromosome 1. Science, 1995; 269: 970-973.

8. Goate A, Chartier-Harlin M-C, Mullan M, et al: 1991. Segregation of a missense mutation in the amyloid precursor protein gene with familial Alzheimer's disease. Nature, 1991; 349: 704-706.

9. Katzman R and Jackson JE: Alzheimer disease: basic and clinical advances. J Am Geriatr Soc, 1991; 39: 516-525.

10. M CKee AC, Kosik KS and Kowall NW: Neuritic pathology and dementia in Alzheimer's disease. Ann Neurol, 1991; 30: 156-165.

11. Terry RD: Ultrastructural alterations in senile dementia. In eds. Katzman R, R.D. Terry RD and Bick, KL.Alzheimer's Disease: Senile Dementia and Related Disorders. New York, NY, Raven Press. 1978; 375-382.

12. Terry RD, Masliak E and Hansen LA: 1994. Structural basis of the cognitive alterations. In eds. Terry RD, Katzman R and Bick KD: Alzheimers disease. New NY, Raven Press. 1994; 179-196.

13.Dyrks T, Dyrks E, Hartmann T, et al:
A myloidogenicity of ßA4-bearing amyloid protein precursor fragments by metal-catalyzed oxidation.J Biol Chem, 1992; 267: 18210-18217.

14. Mann DMA and Esiri M M : The pattern of acquisition of plaques and tangles in the brains of patients under 50 years of age with Down's syndrome. J Neurol Sci, 1989; 89: 169-179.

15. Crystal H, Dickson D, Fuld P, et al: 1988. Clinicopathologic studies in dementia: nondemented subjects with pathologically confirmed Alzheimer's disease. Neurol, 1988; 38: 1682-1687.

16. Arriagada PV, Marzloff $K$ and Hyman BT: Distribution of Alzheimer-type pathologic changes in nondemented elderly individuals matches the pattern in Alzheimer's disease. Neurol, 1992; 42: 1681-1688.

17. Editorial: Amyloid and Alzheimer's disease. Nature Med, 1998;4: 745.

18. Gasparini L, Racchi M, Binetti G, et al: Peripheral markers in testing pathophysiological hypotheses and diagnosing Alzheimer's disease. FASEB J, 1998; 12: 17-34.

19. Selkoe DJ: Translating cell biology into therapeutic advances in Alzheimer's disease. $\mathrm{Na}$ ture, 1999; 399 (Supp): A23-A31.

20. Yankner BA: M echanisms of neuronal degeneration in Alzheimer's disease. Neuron, 1996; 16: 921-932.

21. Hardy JA, Higgins GA: 1992. Alzheimer'e disease: the amyloid cascade hypothesis. Science, 1992; 256: 184-185.

22. Yankner BA: New clues to Azheimer's disease: unraveling the roles of amyloid and tau. Nature Med, 1996; 2: 850-852.

23. SelkoeDJ: Alzheimer's disease: genotypes, phenotypes,and treatments. Science, 1997; 275: 630-631.

24.Dickson DW: The pathogenesis of senile plaques. J Neuropathol Exp Neurol, 1997; 56: 321-338.

25. Harman D: Aging: phenomena and theories. Ann NY Acad Sci, 1998; 850: 1-7.

26. Harman D: Aging: prospects for further increases in the functional life span. Age, 1994; 17: 119-146.

27. Harman D: 1956. Aging: a theory based on free radical and radiation chemistry. J Gerontol, 1956; 11: 298-300.

28. Harman D: 1992. Free radical theory of aging: history. In eds. Emerit I and Chance B, Free Radicals and Aging. Basel, Switzerland, Birkhauser. 1992; 1-10.

29. Harman D: Free radical theory of aging: Increasing the average life expectancy at birth and the maximum life span. J Anti-Aging M ed, 1999; 2: 199-208.

30. Sohal RS and Sohal BH: Hydrogen peroxidere- 
lease by mitochondria increases during aging. Mech Ageing Dev, 1991; 57: 187-202.

31. Ozawa T: 1998. Mitochondrial DNA mutations and age. Ann N Y Acad Sci, 1998; 854: 128-154.

32. Verhasselt $V$, Goldman $M$ and Willems $F$ : Oxidative stress up- regulates IL- 8 and TNFalpha synthesis by human dendritic cells. Eur J Immunol, 1998; 28: 3886-3890.

33. Lue LF, Brachova L, Civin WH and Rogers J: Inflammation, $A ß$ deposition, and neurofibrillary tangle formation as correlates of Alzheimer'sdisease neurodegeneration. J Neuropathol Exper Neurol, 1996; 55: 1083-1088.

34. Strittmatter WJ, Weisgraber KH, Huang DY, et al: Binding of human apoliporotein $\mathrm{E}$ to synthetic amyloid ß peptide: isoform-specific effects and implications for late-onset Alzheimer's disease. Proc Natl Acad Sci USA 1993; 90: 8098-8102.

35. Larsson N-G and Luft R: Revolution in mitochondrial medicine. FEBS Lett. 1999; 455: 199-202.

36. Bonilla E, Tanji K, Hirano, M, et al: Mitochondrial involvement in Alzheimer's disease. Biochim Biophys Acta, 1999; 1410: 171-182.

37. Brown MD, Shoffner JM, Kim YL, et al: Mitochondrial DNA sequence analysis of four Alzheimer's and Parkinson's disease patients. Am J Med Genet, 1996; 61: 283-289.

38. Blacker $D$ and Tanzi RE: The genetics of Alzheimer's disease: Current status and future prospects. Arch Neurol, 1998; 55: 294-296.

39. Davis RE, Miller $S$, Herrnstadt $C$, et al: Mutations in mitochondrial cytochrome $c$ oxidase genes segregate with late-onset Alzheimer's disease. Proc Natl Acad Sci, USA, 1997; 94: 45264531.

40. Hardy J: Amyloid, the presenilins and Alzheimer's disease. Trends NeuroSci, 1997; 20: 154159.

41. Storey E, Spurck T, Pickett-Heaps J, et al: The amyloid precursor protein of Alzheimer's disease is found on the surface of static but not actively motile portions of neurites. Brain Res, 1996; 735: 59-66.

42. Yu G, Chen F, Levesque G, et al: The presenilin 1 protein is a component of a high molecular weight intracellular complexthat contains _catenin. J Biol Chem, 1998; 273: 16470-16475.

43. Jacobsen $H$, Resinhardt $D$, Brockhaust $M$, et al: The influence of endoproteolytic processing of familial Alzheimer's disease presenilin 2 on $A ß_{42}$ amyloid peptideformation. J Biol Sci, 1999; 274: 35233-35239.

44. M arzella L and Glaumann H: 1987. Autophagy, micro-autophagy and crinophagy as mechanisms for protein degradation. In.eds. Glaumann $\mathrm{H}$ and Ballard FJ. Liposomes: Their
Role in Protein Breakdown. New York, NY, Academic Press. 1987; 319-366.

45. Kimberly WT, Xia W, Rahmati T, et al: 2000. The transmembrane aspartates in presenilin 1 and 2 are obligatory for gamma-secretase activity and amyloid ß-protein generation. J Biol Chem, 2000; 275: 3173-3178.

46. Zhang P, Toyoshima C, Yonekura K, et al: Structure of the calcium pump from sarcoplasmic reticulum at 8-A resolution. Nature, 1998;392: 835-839.

47. Auer M, Scarborough GA, Kuhlbrandt W: Three-dimensional map of the plasmamembrane H+ATPase in the open conformation. Nature, 1998; 392: 840-843.

48. MacLennan DH, Rice WJ, Green NM: The mechanism of $\mathrm{Ca} 2+$ transport by sarco(Endo)plasmic reticulum Ca2+ATPases. J Biol Chem, 1997; 272: 28815-28818.

49. Miller RJ: The control of neuronal $\mathrm{Ca} 2+$ homeostasis. Prog Neurobiol, 1991;37: 255-285.

50. Berridge MJ and Irvine RF: Inositol phosphates and cell signalling. Nature, 1989; 341: 197-205.

51. Meszaros LG, M inarovic I and Zahradnikova $A$ : Inhibition of the skeletal muscleryanodine receptor calcium channel by nitric oxi $\mathrm{de}$. FEBS Lett, 1996; 380: 49-52.

52. Xu L, Eu JP, M eissner G and Stamler JS: Activation of the cardiac calcium release channel (ryanodine receptor) by poly-S-nitrosylation. Science, 1998; 279: 234-237.

53. Kimura $Y$, Kurzydlowski K, Tada $M$ and MacLennan. DH: Phospholamban regulates the $\mathrm{Ca} 2+$-ATPase through intramembrane interactions. J Biol Chem, 1996; 271: 2172621731.

54. Hughes G, Starling AP, Sharma RP, East JM and LeeAG: An investigation of the mechanism of inhibition of the Ca2+-ATPase by phospholamban. Biochem J, 1996; 318: 973-979.

55. Levine BA, Patchell VB, Sharma P, et al: Sites on the cytoplasmic region of phospolamban involved in interaction withcalcium-activated ATPase of the sarcoplasmic reticulum. Eur J Biochem, 1999; 264: 905-913.

56. Wang $L H, T u Y P$, Yang $X Y$, et al: Effect of ganglioside GM 3 on the activity and conformation of reconstituted Ca2+ATPase. FEBS Lett, 1996; 388: 128-130.

57. Wang Y, Tsui Z and Yang Y: A ntagonistic effect of ganglioside GM 1 and GM 3 on the activity and conformation of sarcoplasmic reticulum Ca2+ATPase. FEBS Lett. 1999; 457: 144-148.

58. Antipenko AY, Spielman AI and Kirchaberager $M A$ : Interactions of 6-gingerol and ellagic acid with the cardiac sarcoplasmic retic ulum Ca2+-ATPase.J Pharmacol Exper Therap, 1999; 
290: 227-234.

59. Liguri G, Cecchi C, Latorraca L, et al: Alteration of acylphosphatase levels in familia Alzheimer's disease fibroblasts with presenilin gene mutations. Neurosci Lett, 1996; 210: 153-156.

60. Mattson MP, Zhu H, Yu J and Kindy MS: Presenilin-1 mutation increases neuronal vulnerability to focal ischemia in vivo and to hypoxia and glucose deprivation in cell culture: involvement of perturbed calcium homeostasis. J Neurosci, 2000; 20: 1358-1364.

61. Guo Q, Christakos S, Robinson $\mathrm{N}$ and M attson MP: Calbindin D28kblocks the proapoptotic actions of mutant presenlin 1: reduced oxidative stress and preserved mitochondrial function. Proc Natl Acad Sci USA, 1998; 95: 3227-3232.

62. Guo Q, Sebastian L and Sopher BL: Increased vulnerability of hippocampal neurons from presenilin-1 mutant knock-in mice to amyloid ß-peptide toxicity: central roles ofsuperoxide production and caspase activation. J Neurochem, 1999; 72: 1019-1029.

63. Richter C, Gogvadze V and Laffranchi R: Oxidants in mitochondria: from physiology to diseases. Biochim Biophys Acta, 1995; 1271:67-74.

64. Oliver $\mathrm{C}$ and $\mathrm{Holland} \mathrm{AJ}$ : Down's syndromeand Alzheimer'sdisease: a review. Psychological Med, 1986; 16: 307-322.

65. Rumble B, Retallack R, Hilbich $C$, et al: Amyloid $A 4$ protein and its precursor in Down's syndrome and Alzheimer's disease. N Engl J Med, 1988; 320: 1446-1452.

66. Wisniewski KE, Hill AL and Wisniewski HM: Aging and Alzheimer's disease in people with Down's syndrome. In. eds. Lott IT and McCoy EE. Advances in Medical Care. New York, NY, Wiley-Liss. 1992; 167-183.

67. Schuchmann Sand Heinemann U: Increased mitochondrial superoxide generation in neurons from trisomy 16 mice: a model of Down's syndrome. Free Radic Biol Med, 2000; 28: 235-250.

68. Busciglio J,Jankner BA: Apoptosis and increased generation of reactive oxygen species in Down's syndromeneurons in vitro. Nature, 1995; 378: 776-779.

69. Graves AB, WhiteE, Koepsell TD, et al: The association between head traum and Alzheimer's disease. Am J Epidemiol, 1990; 131: 491-501.

70. Roberts GW, Allsop D and Bruton C: The occult aftermath of boxing. J Neurol Neurosurg Psychiat, 1990; 53: 373-378.

71. Guterman A and Smith RW: Neurological sequelae of boxing. Sports M ed, 1987; 4: 194-210.

72. Roberts GW, Gentlemen SM, Lynch A, Graham DI: ßA4 amyloid protein deposition in brain after head trauma. Lancet, 1991; 338: 1422-1423.
73. Adams CWM and Bruton CJ: The cerebral vasculature in dementia pugilistica. J Neurol Neurosurg Psychiat, 1989; 52: 600-6004.

74. Behl C, Davis JB, Lesley R and Schubert D: Hydrogen peroxide mediates amyloid $B$ protein toxicity. Cell, 1994; 77: 817-827.

75. Harman D: Alzheimer's disease: a hypothesis on pathogenesis. J Am Aging Assoc, 2000; 23: 147-161.

76. Harman D: Alzheimer's disease: role of aging in pathogenesis. Ann NY Acad Sci, 2002; 959: 384-395.

76. Emilien GK, Beyreuther $C L$, Masters $L$, M aloteaux JM: Prospects for pharmacological intervention in Alzheimer's Disease. Arch Neurol, 2000; 57: 454-459. 